\title{
The risk of plasma vitamin $A, C, E$ and $D$ deficiency in patients with metabolic syndrome: A case-control study
}

\author{
Małgorzata Godala a, A-D, F, Izabela Materek-Kuśmierkiewicz 2, A, B, D, Dariusz Moczulski', A, E, Maciej Rutkowski3, B,

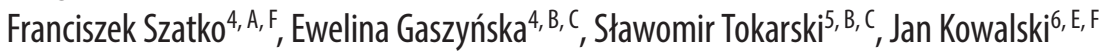 \\ ${ }^{1}$ Department of Nutrition and Epidemiology, Chair of Hygiene and Epidemiology, Medical University of Łódz, Poland \\ ${ }^{2}$ Department of Internal Medicine and Nephrodiabetology, Chair of Internal Diseases and Cardiology, Medical University of Łódz, Poland \\ ${ }^{3}$ Department of Military Toxicology and Radiological Protection, Medical University of Łódz, Poland \\ ${ }^{4}$ Department of Hygiene and Health Promotion, Chair of Hygiene and Epidemiology, Medical University of Łódz, Poland \\ ${ }^{5}$ Faculty of Medicine, University of Rzeszów, Poland \\ ${ }^{6}$ Department of Internal and Infectious Diseases, Medical University of Łódz, Poland \\ A - research concept and design; B - collection and/or assembly of data; C - data analysis and interpretation; \\ $D$ - writing the article; $E$ - critical revision of the article; $F$ - final approval of article
}

\section{Address for correspondence}

Małgorzata Godala

E-mail:malgorzata.godala@umed.lodz.pl

Funding sources

None declared

Conflict of interest

None declared

\section{Acknowledgements}

The study was financed by the Medical University of Łódz (research task №: 502-03/6-024-02/50264-050).

Received on June 01, 2015

Revised on August 07, 2015

Accepted on March 31, 2016

DOI

10.17219/acem/ 62453

\section{Copyright}

Copyright by Author(s)

This is an article distributed under the terms of the

Creative Commons Attribution Non-Commercial License

(http://creativecommons.org/licenses/by-nc-nd/4.0/)

\section{Abstract}

Background. The increasing incidence of metabolic diseases such as obesity or diabetes have made them a major public health problem. Increasing oxidative stress induced by reactive oxygen species, which initiate the oxidative adverse changes in the cell, is mentioned, among other risk factors, to underlie these diseases. Vitamin $A, C$ and $E$ are listed among the non-enzymatic mechanisms counteracting this phenomenon. Vitamin $\mathrm{D}$ deficiency is also associated with cardiovascular diseases.

Objectives. The aim of the study was to assess the risk of vitamin A, C, E and D deficit in the plasma of metabolic syndrome (MS) patients.

Material and methods. The study included 191 patients with MS and 98 subjects without MS. Loglinear analysis was used in the assessment of mutual interactions between the vitamin concentration and the analysis of classification by ROC curves to predict the frequency of vitamin deficiency in MS patients.

Results. A correlation was found between the plasma level of vitamins in the group of MS patients. Vitamin A concentration correlated with that of vitamin C $(r=0.51, p=0.0000)$, vitamin D $(r=0.49$, $p=0.0000)$ and $E(r=0.32, p=0.0001)$. The plasma level of vitamin $D$ correlated with the level of vita$\min E(r=0.46, p=0.00000)$ and vitamin $C(r=0.37, p=0.0000)$. Regression analysis showed a correlation between the concentration of the tested vitamins in patients with MS. Interactions were observed between vitamins C and A and between C and D. HDL cholesterol level was lower in patients with vitamin A deficiency compared to patients with its normal level.

Conclusions. The plasma levels of vitamin A, C, E and D were significantly lower in patients with MS than in healthy subjects and they mutually correlated with each other. The normalization of glucose and HDL level may contribute to the regulation of the concentration of vitamin A in patients with MS.

Key words: metabolic syndrome, antioxidant vitamins, vitamin D deficiency 
The increasing incidence of metabolic diseases such as obesity or diabetes have made them a major public health problem. The accumulation of metabolic risk factors for atherosclerosis, known as metabolic syndrome (MS), has been known for a long time. Increasing oxidative stress induced by reactive oxygen species (ROS), which initiate the oxidative adverse changes in the cell, is mentioned, among other risk factors, to underlie these diseases. Free radicals damage the structure and function of nucleic acids, lipids, proteins and sugars, which in turn leads to changes in the genetic material and to the incidence of cancer, cardiovascular, respiratory and eye diseases and may accelerate the aging process. To defend itself against ROS, the body uses its own antioxidant system as well as antioxidants consumed in the diet. Vitamin A, C and E are listed among the non-enzymatic mechanisms counteracting this phenomenon., ${ }^{1,2}$

Vitamin D deficiency is associated with cardiovascular diseases. Its receptors are located in many organs and tissues and numerous studies have shown that there is an inverse correlation between serum $25(\mathrm{OH}) \mathrm{D}$ level and the occurrence of MS. Vitamin D is involved in the regulation of blood pressure and it is thought to influence lipid metabolism and insulin secretion. Furthermore, numerous studies have shown that its concentration in obese individuals, especially those with abdominal obesity, is significantly lower than among those of normal body composition. Thus, plasma 25(OH)D level has a significant impact on all components of MS. Supplementation of vitamin $\mathrm{D}$, alone or in combination with $\mathrm{Ca}$, as a strategy for the prevention of cardiovascular diseases has raised considerable debate. . $^{3,4}$

The aim of the study was to assess the risk of vitamin A, $\mathrm{C}, \mathrm{E}$ and D deficit in the plasma of MS patients.

\section{Material and methods}

\section{Study population}

The study included 191 patients with MS recruited from the Department of Internal Medicine and Nephrodiabetology, Medical University of Łódz, 101 men and 90 women, aged $30-65$ years (mean $56.73 \pm 7.51$ years).

The control group consisted of 98 subjects, 54 men and 44 women, aged 41-65 years (mean $57.45 \pm 5.24$ years), clinically healthy, without MS.

All of them were nonsmokers and in the last year they had not taken any dietary supplements.

\section{Metabolic syndrome (definition)}

The MS diagnosis was based on IDF (International Diabetes Federation) criteria, stating the type of central obesity (waist circumference in women $\geq 80 \mathrm{~cm}$, in men $\geq 94 \mathrm{~cm}$ ) and 2 of the following risk factors: triglyc- erides $\geq 1.7 \mathrm{mmol} / \mathrm{L}$ or treatment of this disorder, low HDL cholesterol (in women $<1.3 \mathrm{mmol} / \mathrm{L}$, in men $<1.0$ $\mathrm{mmo} / \mathrm{L}$ ) or treatment of the disorder, fasting glucose level $\geq 6.1 \mathrm{mmol} / \mathrm{L}$ or treated type 2 diabetes, blood pressure $\geq 130 / 85 \mathrm{~mm} \mathrm{Hg}$ or treatment of hypertension. ${ }^{5}$

\section{Biochemical analyses}

The mean of 3 blood pressure readings (systolic and diastolic) were measured using a mercury sphygmomanometer.

Fasting blood glucose was determined with a reaction between glucose and ATP catalyzed by hexokinase; TG concentration was enzymatically measured with coupled reactions in which TG was hydrolyzed to produce glycerol; TC was measured with reactions using cholesteryl ester hydrolase, cholesterol oxidase, and peroxidase; HDL was measured using a heparin-manganese precipitation method; LDL was assessed using the Friedewald equation.

The concentration of 25-hydroxy vitamin D (25-OH-D) was assessed with the application of the LIAISON ${ }^{\circledR}$ (DiaSorin, Saluggia, Italy) test using chemiluminescent immunoassay (CLIA) technology. A plasma level of $25(\mathrm{OH})$ D above $30 \mathrm{ng} / \mathrm{mL}$ was considered normal, between $20 \mathrm{ng} / \mathrm{mL}$ and $30 \mathrm{ng} / \mathrm{mL}$ - suboptimal (hypovitaminosis) and below $20 \mathrm{ng} / \mathrm{mL}$ - insufficient (deficiency). ${ }^{3}$

In all patients, the determinations of the plasma level of vitamin A, C and E were performed by spectrophotometric method using a spectrophotometer T60V (PG Instruments, Leicestershire, UK) according to the modified Rutkowski et al. method. ${ }^{6-8}$ Plasma levels of the investigated vitamins were given in $\mu \mathrm{mol} / \mathrm{L}$. Plasma vitamin deficiency was stated for vitamin $\mathrm{A}<0.9 \mu \mathrm{mol} / \mathrm{L}$, for vitamin $\mathrm{C}<36.1 \mu \mathrm{mol} / \mathrm{L}$ and for vitamin $\mathrm{E}<12 \mu \mathrm{mol} / \mathrm{L}^{6-8}$

\section{Anthropometry analyses}

Height was measured using a fixed stadiometer and weight was taken with individuals wearing light clothes and no shoes on a digital scale with a capacity of $200 \mathrm{~kg}$ and accurate to the nearest $100 \mathrm{~g}$. Body mass index (BMI) was calculated as weight $(\mathrm{kg})$ divided by height in meters squared. Waist circumference was measured at the midpoint between the bottom of the rib cage and above the top of the iliac crest during minimal respiration.

\section{Statistical analyses}

Statistical analysis was performed using STATISTICA v. 7.1 PL and Office 2010 software. The normal distribution was determined using the Shapiro-Wilk test. The variables not normally distributed underwent logarithmic transformation $\left(\log _{10}\right)$ before statistical analysis. The comparison between the means of 2 independent groups 
was performed using Student's t test and Mann-Whitney $\mathrm{U}$ test for continuous variables, and chi-square test was applied for dichotomic ones. Correlations were assessed by Pearson's coefficient (r).

Log-linear analysis was used in the assessment of mutual interactions between the vitamin concentration and the analysis of classification by ROC curves (Receiver Operating Characteristic) to predict the frequency of vitamin deficiency in MS patients.

Logistic regression analysis with the estimation of the odds ratio was applied in the assessment of the effect of MS parameters on the risk of vitamin A, C, E and D deficiency. $\mathrm{P}<0.05$ was considered as statistically significant.

The study was approved by the Bioethics Committee of the Medical University of Łódz (No. RNN/556/10/KB).

Table 1. Selected baseline characteristics of study participants

\begin{tabular}{|c|c|c|c|}
\hline \multirow{2}{*}{ Characteristics } & MS $(n=191)$ & Without MS ( $\mathrm{n}=98)$ & \multirow{2}{*}{$\mathrm{p}$-value } \\
\hline & mean $\pm S D / \%(n)$ & mean $\pm S D / \%(n)$ & \\
\hline Age [years] & $56.73 \pm 7.51$ & $57.45 \pm 5.24$ & $0.5347 a$ \\
\hline Sex [\% women] & $47.12(90)$ & $44.90(44)$ & $0.3187 a$ \\
\hline BMI $\left[\mathrm{kg} / \mathrm{m}^{2}\right]$ & $35.16 \pm 5.91$ & $28.04 \pm 2.52$ & $<0.0001 a$ \\
\hline Waist [cm] & $114.34 \pm 10.78$ & $95.96 \pm 11.21$ & $<0.0001 a$ \\
\hline $\mathrm{SBP}[\mathrm{mmHg}]$ & $145.98 \pm 17.45$ & $127.87 \pm 11.65$ & $<0.0001 b$ \\
\hline $\mathrm{DBP}[\mathrm{mmHg}]$ & $88.72 \pm 9.25$ & $81.52 \pm 7.47$ & $<0.0001 b$ \\
\hline GLc [mmol/L] & $7.68 \pm 2.28$ & $5.12 \pm 0.57$ & $<0.0001 b$ \\
\hline $\mathrm{TG}[\mathrm{mmol} / \mathrm{L}]$ & $1.98 \pm 0.72$ & $1.45 \pm 0.16$ & $<0.0001 b$ \\
\hline $\mathrm{TC}[\mathrm{mmol} / \mathrm{L}]$ & $4.39 \pm 1.16$ & $4.49 \pm 0.79$ & $0.8171 a$ \\
\hline $\mathrm{HDL}[\mathrm{mmol} / \mathrm{L}]$ & $1.07 \pm 0.21$ & $1.32 \pm 0.31$ & $<0.0001 a$ \\
\hline $\mathrm{LDL}[\mathrm{mmol} / \mathrm{L}]$ & $2.93 \pm 0.84$ & $2.76 \pm 0.72$ & $<0.0001 a$ \\
\hline $25(\mathrm{OH}) \mathrm{D}[\mathrm{ng} / \mathrm{mL}]$ & $13.54 \pm 7.91$ & $27.71 \pm 10.26$ & $<0.0001 a$ \\
\hline Vitamin A [ $\mu \mathrm{mol} / \mathrm{L}]$ & $1.368 \pm 0.35$ & $1.821 \pm 0.575$ & $<0.0001 a$ \\
\hline Vitamin C [ $\mu \mathrm{mol} / \mathrm{L}]$ & $31.14 \pm 8.91$ & $57.83 \pm 17.85$ & $<0.0001 a$ \\
\hline Vitamin E [umol/L] & $12.69 \pm 2.46$ & $25.61 \pm 2.98$ & $<0.0001 a$ \\
\hline 25(OH)D deficiency [\%] & $81.15(155)$ & $23.47(23)$ & $<0.0001 c$ \\
\hline Vitamin A deficiency [\%] & $15.71(30)$ & $1.02(10$ & $<0.0001 c$ \\
\hline Vitamin C deficiency [\%] & $79.58(152)$ & $8.16(8)$ & $<0.0001 c$ \\
\hline Vitamin E deficiency [\%] & $40.31(77)$ & $1.02(1)$ & $<0.0001 c$ \\
\hline
\end{tabular}

$\mathrm{a}$ - Student's t test; $\mathrm{b}-$ Mann-Whitney $U$ test; $\mathrm{c}-\chi^{2}$ test.

\section{Results}

The study included 191 patients with MS and 98 controls without MS. Table 1 presents the characteristics of the tested subjects. As expected, BMI, waist circumference, systolic and diastolic blood pressure, the level of blood glucose, TG and LDL cholesterol were higher in MS patients, whereas HDL level was lower than in subjects without MS. There were no significant differences in total cholesterol concentration in MS patients and controls. The gender and age of the tested subjects did not differentiate significantly the investigated parameters. Mean concentrations of all the studied vitamins were significantly lower in patients with MS than in the control group. Deficiency of the tested vitamins was observed significantly more frequently among the MS patients (Table 1). Gender and age did not affect either the mean concentrations of the tested vitamins or the incidence of their deficiency.

A correlation was found between the plasma level of the vitamins in the group of MS patients. Vitamin A concentration correlated with that of vitamin $C(r=0.51, p=0.0000)$, vitamin $\mathrm{D}(\mathrm{r}=0.49, \mathrm{p}=0.0000)$ and $\mathrm{E}$ $(\mathrm{r}=0.32, \mathrm{p}=0.0001)$. The plasma level of vitamin D correlated with the level of vitamin $\mathrm{E}$ $(\mathrm{r}=0.46, \mathrm{p}=0.00000)$ and vitamin $\mathrm{C}(\mathrm{r}=0.37$, $p=0.0000)$. No correlation was observed between the plasma level of vitamins $C$ and $E$.

Regression analysis showed a correlation between the concentration of the tested vitamins in patients with MS. Interactions were observed between vitamins $\mathrm{C}$ and $\mathrm{A}$ and between $C$ and $D$ (Fig. 1). Moreover, on the basis of the data on vitamin A, C, E and D deficiency/normal plasma levels, the predicted incidence was determined of their deficiency in patients with MS. The highest predictive value was obtained for vitamin $\mathrm{E}$, then for vitamins $\mathrm{C}$ and $\mathrm{D}$ and the lowest for vitamin $\mathrm{A}$ (Fig. 2).

The vitamin $C$ level was lower in patients with vitamin A deficiency in relation to patients with normal vitamin A level $(22.20 \pm 3.60$ $\mu \mathrm{mol} / \mathrm{L}$ vs $32.88 \pm 10.99 \mu \mathrm{mol} / \mathrm{L}, \mathrm{p}=0.0003)$ and the concentration of vitamin $\mathrm{A}$ was lower in patients with vitamin $\mathrm{C}$ deficiency compared to patients with its normal level $(1.34 \pm$ $0.42 \mu \mathrm{mol} / \mathrm{L}$ vs $1.77 \pm 0.29 \mu \mathrm{mol} / \mathrm{L}, \mathrm{p}=0.009)$. It has been demonstrated that vitamin $\mathrm{C}$ deficiency increased 3.5-fold the risk of vitamin A deficiency in patients with MS.

HDL cholesterol level was lower in patients with vitamin A deficiency compared to patients with its normal level $(0.76 \pm 0.41$ $\mathrm{mmol} / \mathrm{L}$ vs $1.10 \pm 0.29 \mathrm{mmol} / \mathrm{L}, \mathrm{p}=0.03)$. 
Fig. 1. Log-linear correlation between the level of vitamin A, C, E and D in the plasma of MS patients

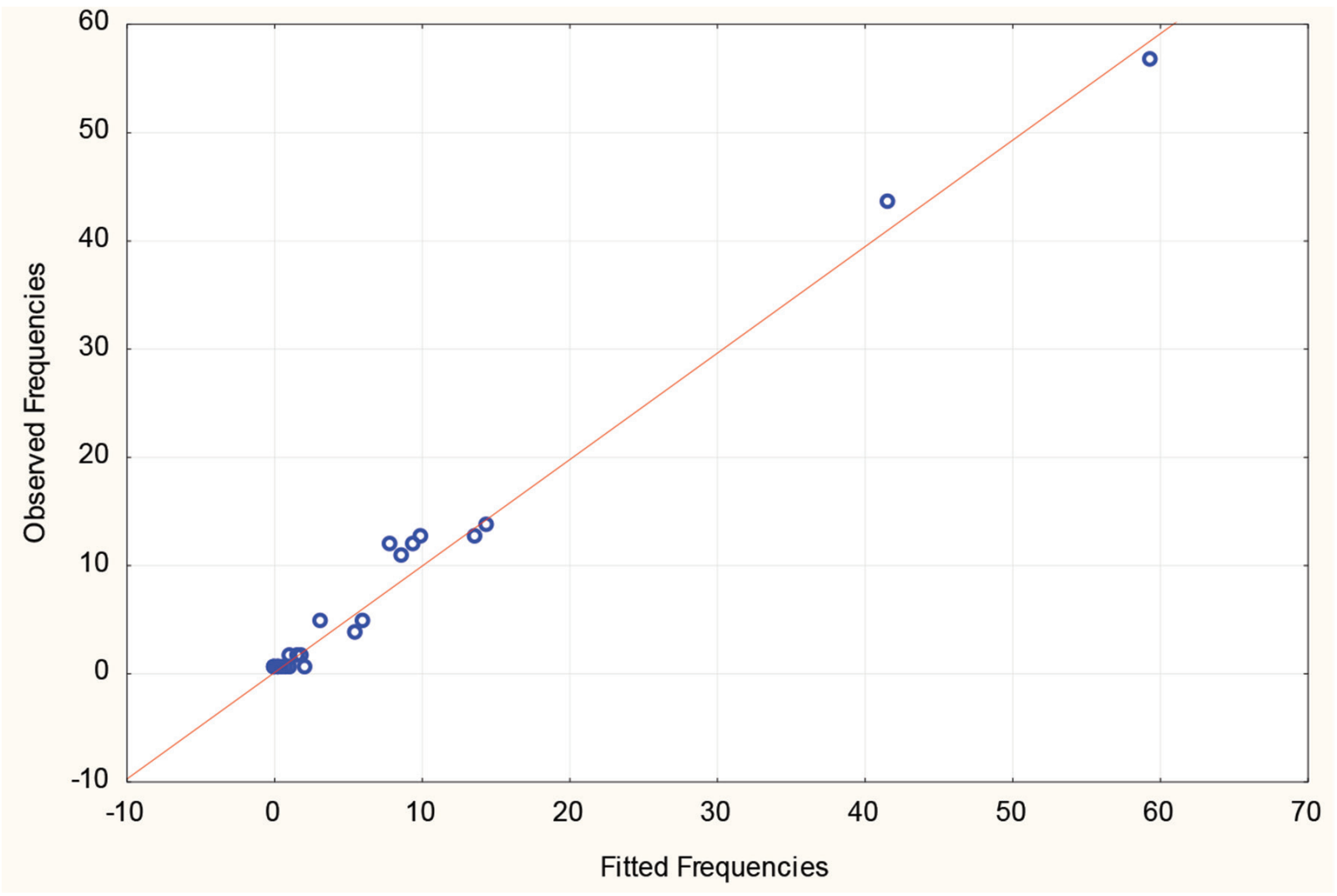

Fig. 2. Predicted prevalence of vitamin A, C, E and D deficiency in MS patients

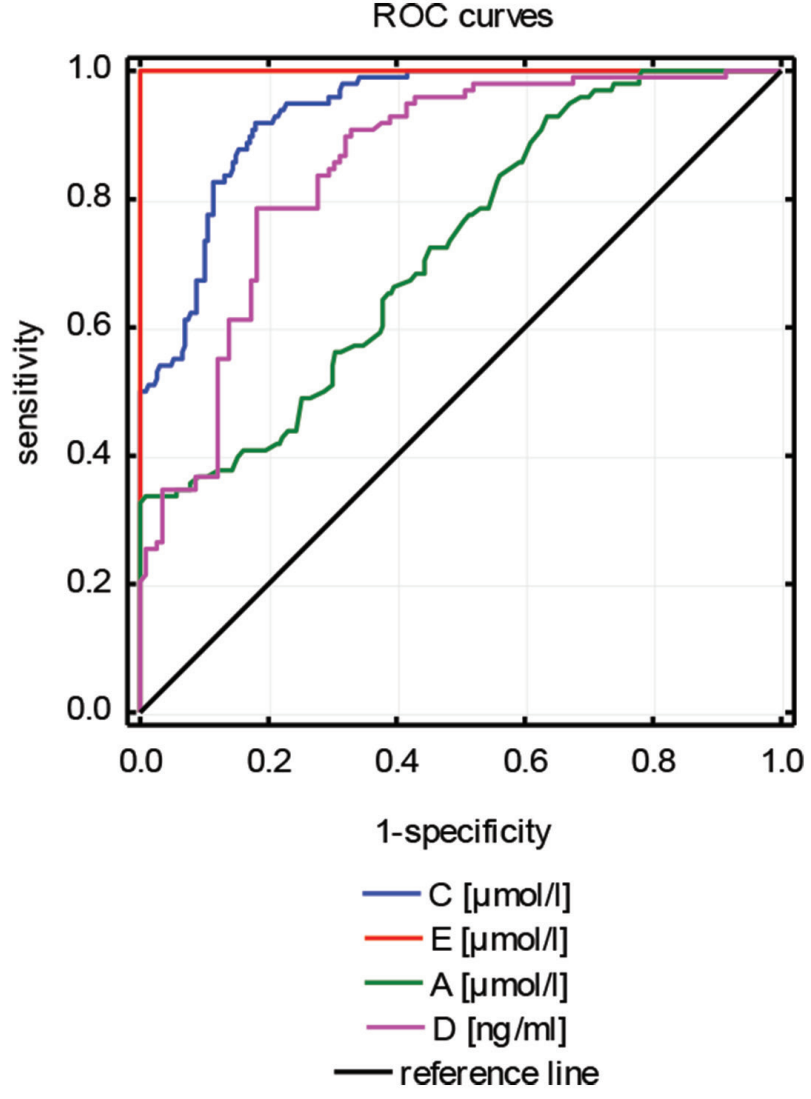

It was also found that individuals with vitamin A deficiency have higher glucose concentration than MS patients with normal vitamin A level $(8.91 \pm 3.58 \mathrm{mmol} / \mathrm{L}$ vs $6.75 \pm 5.56 \mathrm{mmol} / \mathrm{L}, \mathrm{p}=0.04$ ) and hyperglycemia increased 6-fold the risk of vitamin A deficiency.

\section{Discussion}

Reactive oxygen species (ROS), a natural product of cellular metabolism, may have a beneficial effect on cell function (to help fight infections, as secondary transmitters stimulating cellular signal transduction pathways) or can be an etiological factor of metabolic disorders.

Adverse effects are associated with excessive lipid peroxidation, protein and DNA damage which disrupts proper cell functioning. The effect of ROS activity depends on the efficiency of antioxidant mechanisms in the cell. In addition to the enzymatic mechanisms, such as superoxide dismutase, glutathione peroxidase and catalase, there are non-enzymatic mechanisms, which include vitamins $\mathrm{A}, \mathrm{C}$ and $\mathrm{E}$.

Antioxidant vitamins are an important element of the body's non-enzymatic antioxidant barrier and their proper concentration determines the protection against ROS. It has been shown from our previous studies and the studies by other authors that the concentrations of vitamins $\mathrm{A}, \mathrm{C}$ and $\mathrm{E}$ are lower in patients with cardiovas- 
cular diseases than in healthy subjects, even with their appropriate intake from diet. ${ }^{1,2,9}$ Cardiovascular and metabolic diseases are also thought to be associated with vitamin D deficiency. Although vitamin D is not included among antioxidant vitamins, it has been shown from research studies carried out in different countries that vitamin D has an impact on the components of MS and its concentration in patients with metabolic disorders is significantly lower than in healthy individuals. ${ }^{4,10}$ In our study, we attempted to assess the risk of deficiency of these vitamins in patients with MS.

Among MS patients, we found a significant deficiency of all the investigated vitamins, both with regard to their mean concentrations (significantly lower compared to healthy subjects) and the frequency of their deficiency levels. Low levels of vitamin A, C and E in patients with cardiovascular diseases have been observed by other authors, but there have been no studies that would assess the scale of the phenomenon, that is the prevalence of the deficiency of antioxidant vitamins in the population of healthy subjects and those with MS. ${ }^{11-14}$ Vitamin D has been discussed in the literature more often. Its low levels in MS patients have been demonstrated in numerous studies and the prevalence of its deficiency is defined as common not only among patients with cardiovascular diseases, but also in the healthy population. ${ }^{15-20}$

The problem of simultaneous occurrence of the deficiency of antioxidant vitamins in MS patients requires further research. In our study, we have shown a correlation between vitamin A, C, E and D level in patients with MS. The strongest correlations were observed between the plasma level of vitamin A and D, D and E, and A and C. We have also evaluated the risk of the deficiency of the tested vitamins in patients with MS and the highest prediction value of deficiency level was obtained for vitamin E, whereas the lowest was for vitamin A. Moreover, we have shown that the concentration of vitamin $\mathrm{C}$ was lower in patients with deficiency of vitamin A and vitamin $\mathrm{C}$ deficiency 3.5fold increased the risk of vitamin A deficiency.

In the available literature there are studies on the interactions that occur between antioxidant vitamins to prevent mutual degradation or promote regeneration. Vitamin $C$ is an essential cofactor in many processes of systemic biosynthesis. It participates in metabolic processes as a substance transferring electrons, interacts in the synthesis of collagen, and is involved in the metabolism of fats, cholesterol and bile acids. Vitamin $\mathrm{C}$ has proven to be one of the most potent antioxidants. The coupled pair of its forms, oxidized and reduced, creates a redox system capable of reducing ROS that are toxic to cells. ${ }^{1,9}$ Furthermore, it has been shown that ascorbic acid is involved in the regeneration of hydrophobic antioxidants, such as $\alpha$-tocopherol and $\beta$-carotene from the radical form. It is assumed that this reaction takes place on the surface of cell membranes. Ascorbate reduces the tocopherol radical creating an ascorbyl radical. This reaction is possible because of chroman rings in tocopherol molecules which face the outside of the cell membrane and can react with ascorbate found in an aqueous medium. Also, vitamin $\mathrm{E}$ protects retinol esters from oxidation, which is conducive to maintaining its proper concentration. ${ }^{21}$ In our study, we found no correlation between the concentration of vitamin $C$ and vitamin $E$. This could result from the fact that in MS patients ascorbic acid regenerating $\alpha$-tocopherol undergoes degradation. ${ }^{22}$

Among the components of MS, the level of glucose and HDL-cholesterol affected the concentration of vitamin A. Thus, subjects with vitamin A deficiency had lower HDL-cholesterol levels and higher glucose concentration. It was also shown that hyperglycemia increased up to 6-fold the risk of vitamin A deficiency in these patients. Vitamin A is a set of compounds that includes retinol, retinal and carotenoids. Vitamin A's antioxidant properties have been frequently reported in vivo and in vitro. $^{23,24}$ They are exhibited at low (physiological) oxygen partial pressure. Retinol can react with peroxide radicals (ROO •), thereby it interrupts the chain reaction of lipid peroxidation to form hydroperoxides ( $\mathrm{ROOH})$. Furthermore, vitamin A is capable of directly reacting with ROS to form a 5,6-epoxide retinoid. ${ }^{24}$ Carotenoids also exhibit potent antioxidant properties. In addition to their capacity to scavenge peroxyl radicals $(\mathrm{ROO} \bullet$ ) they are effective singlet oxygen quenchers. ${ }^{23}$ An inverse correlation between vitamin A and E level and the risk of cardiovascular diseases was found in many case-control and prospective observational studies. ${ }^{1,9,12}$ This protective effect was attributed to their antioxidant properties. However, clinical trials that evaluated interventions designed to confirm the cause-effect nature of these correlations failed to confirm the results of observational studies. ${ }^{25}$ The reports of New York researchers from Weill Cornell Medical College showed that a low level of vitamin A can lead to degradation of pancreatic $\beta$ cells producing insulin in patients with type 2 diabetes. This means faster progressive development of the disease and a higher risk of complications. ${ }^{26}$ The research was conducted on laboratory animals diagnosed with pancreatic $\beta$-cell atrophy after elimination of vitamin A from the diet. After its reintroduction into the diet, pancreatic $\beta$ cells began to regenerate. Numerous clinical studies have demonstrated the important role of vitamin $\mathrm{A}$ in the production of pancreatic cells in fetal life, but there are no studies that would confirm this relationship in adults. Still, it has not been clarified whether vitamin A deficiency results from its participation in the pathogenesis of diabetes, inadequate intake from the diet or from metabolic defect. The question of the possible involvement of vitamin A deficiency in the pathogenesis of diabetes mellitus type 1 and 2 will require further studies.

Further research is also needed to assess the validity and effectiveness of possible implementation of antioxidant vitamin supplements in these patients. Although 
our studies suggest such a need, the results of studies available in the literature on the effect of vitamin supplements on cardiovascular complications are contradictory. Some authors showed a reduction in oxidative stress, decrease of the risk of cancer and cardiovascular diseases and reduced overall mortality after application of antioxidant vitamin (A, C and E) supplements. ${ }^{22,27,28}$ Other studies have demonstrated that the effect of vitamins depends on many factors, such as smoking, exposure to environmental chemicals, rate of the deficiency of supplemented vitamins or a dose of vitamin preparations and their type. ${ }^{29,30}$ Uncontrolled and excessive use of antioxidant vitamin supplements, especially in patients with corrected deficiency, often results in a different effect, i.e. the intensification of oxidative stress and increased risk of cardiovascular complications. Exceptionally frequently, these types of adverse effects are attributed to vitamin $C$ and E. ${ }^{28-30}$ Thus, the key issue when planning vitamin supplementation in patients with MS seems to be the dosage and preparation composition determined on an individual basis.

\section{Conclusions}

The plasma levels of vitamin A, C, E and D were significantly lower in patients with MS than in healthy subjects and they mutually correlated with each other. Particular correlation was found between vitamin $\mathrm{A}$ and $\mathrm{C}$, at the same time vitamin $\mathrm{C}$ deficiency increased 3.5 -fold the risk of vitamin A deficiency in these patients. Moreover, we have shown that hyperglycemia increased the risk of vitamin A deficiency and the concentration of HDL cholesterol was significantly lower in patients with this vitamin deficiency. Thus, the normalization of glucose and HDL level may contribute to the regulation of the concentration of vitamin A in patients with MS.

\section{References}

1. Ford ES, Mokdad AH, Giles WH, Brown DW. The metabolic syndrome and antioxidant concentration. Findings from the Third National Health and Nutrition Examination Survey. Diabetes. 2003;52:2346-2352.

2. Beydoun MA, Shroff MR, Chen X, Beydoun HA, Wang Y, Zonderman AB. Serum antioxidant status is associated with metabolic syndrome among U.S. adults in recent national surveys. $J$ Nutr. 2011;141:903-913.

3. Płudowski P, Karczmarewicz E, Bayer M, et al. Practical guidelines for the supplementation of vitamin $D$ and the treatment of deficits in Central Europe - recommended vitamin D intakes in the general population and groups at risk of vitamin D deficiency. Pol J Endocrinol. 2013;64(3):1-9.

4. Muscogiuri G, Sorice GP, Ajjan R, et al. Can vitamin D deficiency cause diabetes and cardiovascular diseases? Present evidence and future perspectives. Nutr Metab Cardiovasc Dis. 2012;22:81-87.

5. Alberti KG, Zimmet P, Shaw J. IDF Epidemiology Task Force Consensus Group. The metabolic syndrome - a new worldwide definition. Lancet. 2005;366:1059-1062.

6. Rutkowski M, Grzegorczyk K, Greger J. Adaptation of the phosphotungstate method to determine reduced and oxidized vitamin $\mathrm{C}$ in blood plasma. Zeitschr Naturforsch. 2004;59:762-767.
7. Rutkowski M, Grzegorczyk K, Kędziora J. Laboratory convenient modification of Bessey method for vitamin A determination in blood plasma. J Physiol Pharmacol. 2006;57:221-226.

8. Rutkowski M, Grzegorczyk K, Paradowski MT. Colorimetric determination of total vitamin $\mathrm{E}$ concentration in plasma - own modification of Tsen's method. Diagn Lab. 2005;41:375-385.

9. Cahill L, Corey PN, El-Sohemy A. Vitamin C deficiency in a population of young Canadian adults. Am J Epidemiol. 2009;170:464-471.

10. Muldowney S, Lucey AJ, Paschos G, et al. Relationship between vitamin $D$ status and cardio-metabolic risk factors in young European adults. Ann Nutr Metab. 2011;58(2):85-93.

11. Illison VK, de Oliveira AM, Rondó PHC, D'Abronzo FH, Campos KF. The relation between plasma alpha-tocoferol concentration and vitamin $\mathrm{E}$ intake in patients with type 2 diabetes mellitus. Int $J$ Vitam Nutr Res. 2011;81:12-20.

12. Odum EP, Orluwene CG, Ejilemele AA, Wakwe VC. Antioxidant status of subject with metabolic syndrome in Port Harcourt, Nigeria. Niger Postgrad Med J. 2012;19:199-203.

13. Sharma P, Mishra S, Ajmera P, Mathur S. Oxidative stress in metabolic syndrome. Indian J Clin Biochem. 2005;20:145-149.

14. Singh RB, Ghosh S, Niaz MA, et al. Dietary intake, plasma levels of antioxidant vitamins and oxidative stress in relation to coronary artery disease in elderly subjects. Am J Cardiol. 1995;76(17):1233-1238.

15. Vacek JL, Vanga SR, Good M, Lai SM, Lakkireddy D, Howard PA. Vitamin $D$ deficiency and supplementation and relation to cardiovascular health. Am J Cardiology. 2012;109:359-363.

16. Botella-Carretero Jl, Alvarez-Blasco F, Villafruela JJ, Balsa JA, Vázquez C, Escobar-Morreale HF. Vitamin D deficiency is associated with the metabolic syndrome in morbid obesity. Clin Nutr. 2007;26:573-580.

17. Forrest KYZ, Stuhldreher WL. Prevalence and correlates of vitamin D deficiency in US adults. Nutr Res. 2010;31:48-54.

18. John WG, Noonan K, Mannan N, Boucher BJ. Hypovitaminosis $\mathrm{D}$ is associated with reductions in serum apolipoprotein A-I but not with fasting lipids in British Bangladeshis. Am J Clin Nutr. 2005;82:517-522.

19. Chiu KC, Go VLW, Saad MF. Hypovitaminosis D is associated with insulin resistance and $\beta$ cell dysfunction. Am J Clin Nutr. 2004;79:820-825.

20. Hypponen E, Power C. Hypovitaminosis D in British adults at age $45 \mathrm{y}$ : Nationwide cohort study of dietary and lifestyle predictors. Am J Clin Nutr. 2007;85:860-868.

21. Czernichow S, Vergnaud AC, Galan P, et al. Effects of long-term antioxidant supplementation and association of serum antioxidant concentration with risk of metabolic syndrome in adults. Am J Clin Nutr. 2009;90:329-335.

22. Li Y, Schellhorn HE. New developments and novel therapeutic perspectives for vitamin C. J Nutr. 2007;137:2171-2184.

23. Palace VP, Khaper N, Qin Q, Singal PK. Antioxidant potentials of vitamin $\mathrm{A}$ and carotenoids and their relevance to heart disease. Free Radic Biol Med. 1999;26:746-761.

24. Edge R, McGarvey DJ, Truscott TG. The carotenoids as anti-oxidants - a review. J Photochem Photobiol. 1997;41:189-200.

25. Vivekananthan DP, Penn MS, Sapp SK, Hsu A, Topol EJ. Use of antioxidant vitamins for the prevention of cardiovascular disease: meta-analysis of randomised trials. Lancet. 2003;361:2017-2023.

26. Trasino SE, Benoit YD, Gudas LJ. Vitamin A deficiency causes hyperglycemia and loss of pancreatic $\beta$-cell mass. J Biol Chem. 2015;290:1456-1473.

27. Pocobelli G, Ulrike P, Kristal AR, White E. Use of supplements of multivitamins, vitamin $C$, and vitamin $E$ in relation to mortality. Am J Epidemiol. 2009;170:472-83.

28. Soni MG, Thurmind S, MillerER, Spriggs T, Bendich A, Omaye ST. Safety of vitamins and minerals: Controversies and perspective. Toxicol Science. 2010;118(2):348-355.

29. Bergström T, Bergman J, Möller L. Vitamin A and C compounds permitted in supplements differ in their abilities to affect cell viability, DNA and the DNA nucleoside deoxyguanosine. Mutagenesis. 2011;26(6):735-744.

30. Mayne ST. Oxidative stress, dietary antioxidant supplements, and health: Is the glass half full or half empty? Cancer Epidemiol Biomarkers Prev. 2013;22:2145-2147. 